\title{
ROOT FORMATION OF BLACK COTTONWOOD CUTTINGS IN RELATION TO REGION OF PARENT SHOOT ${ }^{1}$
}

\section{W. J. BLOOMBERG ${ }^{2}$}

W. J. Bloomberg graduated Bachelor of Science in Forestry, University of Wales, 1943. In 1947 he was employed by the Abitibi Power and Paper Co., Sault Ste. Marie, Ontario, in forest inventory. In 1948 he joined the Alberta Forest Service as assistant superintendent, Clearwater Forest Reserve. From 1953 to 1956 he was editor of Canadian Pulp and Paper Industry. In 1958 he joined the Forest Biology Laboratory, Victoria, B.C., and has been engaged as a Research Officer in a study of poplar disease. He is currently taking his Ph.D. in Forest Pathology at the University of British Columbia where his thesis subject concerns diseases of poplars.

\section{ABSTRACT}

Shoots of one-year-old Populus trichocarpa Torr. and Gray were collected just after breaking of dormancy from a nursery at Lulu Island, B. C. The shoots were divided into four sections of equal length and placed in an atmosphere of $100 \%$ relative humidity at a constant temperature of $4^{\circ} \mathrm{C}$. After one month the quarters were sampled to determine the number and length of adventitious roots formed and the number of new shoots. Significant differences were found in the number and length of roots produced in different quarters of the shoot but not in the number of new shoots. There were also significant differences in root length between clones. The most numerous and longest roots occurred on the lowest quarter of the shoot and decreased acropetally. The data suggest the better performance of cuttings of $\mathbf{P}$. trichocarpa from the lower portions of the shoot and the importance of vigor in individual clones.

\section{INTRODUCTION}

Populus trichocarpa Torr. and Gray, black cottonwood, is at present being propagated to provide cutting material for commercial plantation establishment in British Columbia. The method of propagation is by stump culture in the nursery, each stump or stock bearing several shoots suitable for subdivision into cuttings. The cuttings are then set out at the plantation site in an unrooted condition.

A varying survival rate of such cuttings has been observed. Since it is the practice to obtain several cuttings from each shoot, it is of interest to know if the position from which the cutting is taken has any bearing on its subsequent performance. A study was therefore carried out to examine this relationship.

\section{METHOD}

One-year-old black cottonwood shoots, excluding minor laterals, were harvested from a nursery at Lulu Island, B.C., just after breaking of dormancy

\footnotetext{
${ }^{2}$ Contribution No. 489 from the Forest Biology Division, Science Service, Departmeat of Agriculture, Ottawa. Received for publication August 10, 1958.

- Forest Biology Laboratory, Victoria, B.C.
} 
and grouped according to the individual stumps from which they were taken. Each group, therefore, constituted a genetic entity and was labelled a "clone". The shoots from each clone were divided into four sections of equal length, approximately $60 \mathrm{cms}$. The quarters were numbered one to four, one being the uppermost morphologically and four being the lowest. They were placed in polyethylene bags, and stored in the dark at a constant temperature of $4^{\circ} \mathrm{C}$. The atmosphere in the bags immediately became saturated and remained so for the duration of the experiment. After one month the cuttings were removed from the bags and sampled for adventitious root and shoot development.

Ten clones were selected at random and from each quarter of each clone two random samples of $10 \mathrm{cms}$. were selected along the axis of the stem. The number of roots, root length, and number of shoots were tallied in each sample.

\section{RESULTS}

Roots and new shoots from lateral buds were formed in the saturated atmosphere of the bags and were easily counted and measured. The appearance of the roots was vigorous and normal (see Fig. 1). New shoots were etiolated because of the darkness in which they had been held.

\section{Number of Roots}

Although no significant difference could be determined between the fourth or lowest and the third quarters, all other differences were significant ( $p$ less than .01). The number of roots increased from the top quarter towards the bottom. There was no significant difference ( $p$ less than .05 ) between the clones in their ability to produce roots (Table I).

TABLE I

Number of Adventitious Roots Formed in Different Quarters of Black Cottonwood Shoots. (Total of Two 10-CM. Samples)

\begin{tabular}{cccccc}
\hline Clone No. & $\begin{array}{c}\text { 1st } \\
\text { Quarter }^{3}\end{array}$ & $\begin{array}{c}\text { No. of Roots Occurring in: } \\
\text { Quarter }\end{array}$ & $\begin{array}{c}\text { 3rd } \\
\text { Quarter }\end{array}$ & $\begin{array}{c}\text { 4th } \\
\text { Quarter }\end{array}$ & $\begin{array}{c}\text { Total of } \\
\text { Four Quarters }\end{array}$ \\
\hline 1 & 7 & 9 & 13 & 16 & 45 \\
2 & 6 & 7 & 13 & 26 & 52 \\
4 & 0 & 9 & 18 & 24 & 51 \\
5 & 0 & 3 & 8 & 10 & 21 \\
7 & 6 & 10 & 19 & 22 & 57 \\
10 & 1 & 10 & 24 & 17 & 52 \\
11 & 0 & 2 & 27 & 12 & 41 \\
16 & 0 & 8 & 26 & 26 & 60 \\
18 & 0 & 17 & 22 & 25 & 64 \\
19 & 1 & 14 & 15 & 19 & 49 \\
Average & 2.1 & 8.9 & 18.5 & 19.7 & \\
\hline
\end{tabular}

${ }^{3}$ Quarter 1 is top and Quarter 4 is bottom of shoot. 


\section{Length of Roots}

Roots showed a tendency to increase in length basipetally, although only those borne on the fourth quarter showed a significant difference ( $p$ less than $.01)$ from those on other quarters. There was a highly significant difference ( $p$ less than .01) between the clones as to the root length produced by them. Comparisons between individual clones showed a number of significant differences (Table II).

TABLE II

Average Length of Adventitious Roots Formed in Different Quarters of Black Cottonwood Shoots. (Millimeters).

\begin{tabular}{cccccc}
\hline Clone No. & $\begin{array}{c}\text { 1st } \\
\text { Quarter }\end{array}$ & $\begin{array}{c}\text { Average Length of Roots Occurring in: } \\
\text { 2nd } \\
\text { Quarter }\end{array}$ & $\begin{array}{c}\text { 3rd } \\
\text { Quarter }\end{array}$ & $\begin{array}{c}\text { 4th } \\
\text { Quarter }\end{array}$ & $\begin{array}{c}\text { Average } \\
\text { for Clone }\end{array}$ \\
\hline 1 & 20 & 20 & 27.5 & 35 & 26.4 \\
2 & 35 & 25 & 30 & 32.5 & 30.0 \\
4 & - & 13.5 & 17.5 & 22.5 & 17.8 \\
5 & - & 5 & 5 & 18.5 & 10.4 \\
7 & 6 & 35 & 15.5 & 45 & 23.0 \\
10 & 13 & 20 & 20 & 22.5 & 19.7 \\
11 & - & 9.5 & 30 & 40 & 26.3 \\
16 & - & 32.5 & 42.5 & 65 & 46.6 \\
18 & - & 22.5 & 45 & 46 & 37.8 \\
19 & 50 & 23 & 30 & 50 & 34.3 \\
Average & 21.7 & 21.4 & 26.1 & 36.7 & \\
\hline
\end{tabular}

Number of Shoots

No significant difference was found in the number of new shoots formed by different clones in different quarters (Table III).

TABLE III

Number of New Shoots Formed in Different Quarters of Black Cottonwood Shoots. (Total of Two 10-CM. Samples)

\begin{tabular}{cccccc}
\hline Clone No. & $\begin{array}{c}\text { No. of New Shoots Occurring in } \\
\text { Quarter }\end{array}$ & $\begin{array}{c}\text { 2nd } \\
\text { Quarter }\end{array}$ & $\begin{array}{c}\text { 3rd } \\
\text { Quarter }\end{array}$ & $\begin{array}{c}\text { 4th } \\
\text { Quarter }\end{array}$ & $\begin{array}{c}\text { Total of } \\
\text { Four Quarters }\end{array}$ \\
\hline 1 & 1 & 2 & 2 & 2 & 7 \\
2 & 0 & 0 & 1 & 1 & 2 \\
4 & 1 & 2 & 0 & 2 & 5 \\
5 & 0 & 0 & 0 & 0 & 0 \\
7 & 0 & 0 & 0 & 4 & 4 \\
10 & 0 & 0 & 1 & 0 & 1 \\
11 & 0 & 0 & 0 & 1 & 1 \\
16 & 2 & 2 & 1 & 4 & 9 \\
18 & 0 & 2 & 0 & 1 & 3 \\
19 & 2 & 1 & 0 & 0 & 3 \\
Average & 0.6 & 0.9 & 0.5 & 1.5 & \\
\hline
\end{tabular}




\section{Discussion}

Van der Lek (1) has described the occurrence of root pre-initials at points where the xylem rays intersect the cambial layer. In the light of the results obtained, it would appear that either the number of initials decreases acropetally or the gradient of vigor of development decreases in the same direction. The likelihood of earlier adventitious root development in the lower region of the stem is ruled out, since it is well established that seasonal cambial activity is initiated at the terminal bud and spreads generally in a basipetal direction.

Lack of clonal differentiation as measured by number of roots produced may be explained partly on the grounds that there was no justification for assuming genetic differences between stumps. The clonal differences in root length may, therefore, reflect non-genetic effects.

The practical conclusion to be drawn from the results appears to be that better rooting performance of cuttings is made by the lower half of the stem of black cottonwood. The need for investigating factors involved in development of root initials is indicated.

\section{REFERENCES}

1. VAN DER LEK, H. A. A. 1930. Anatomical structure of woody plants in relation to vegetative propagation. Proceedings of the International Horticultural Congress. 




FIGURE 1

Paired samples from a clone of black cottonwood showing the increase in adventitious roots from the tip to the base of the shoot. 

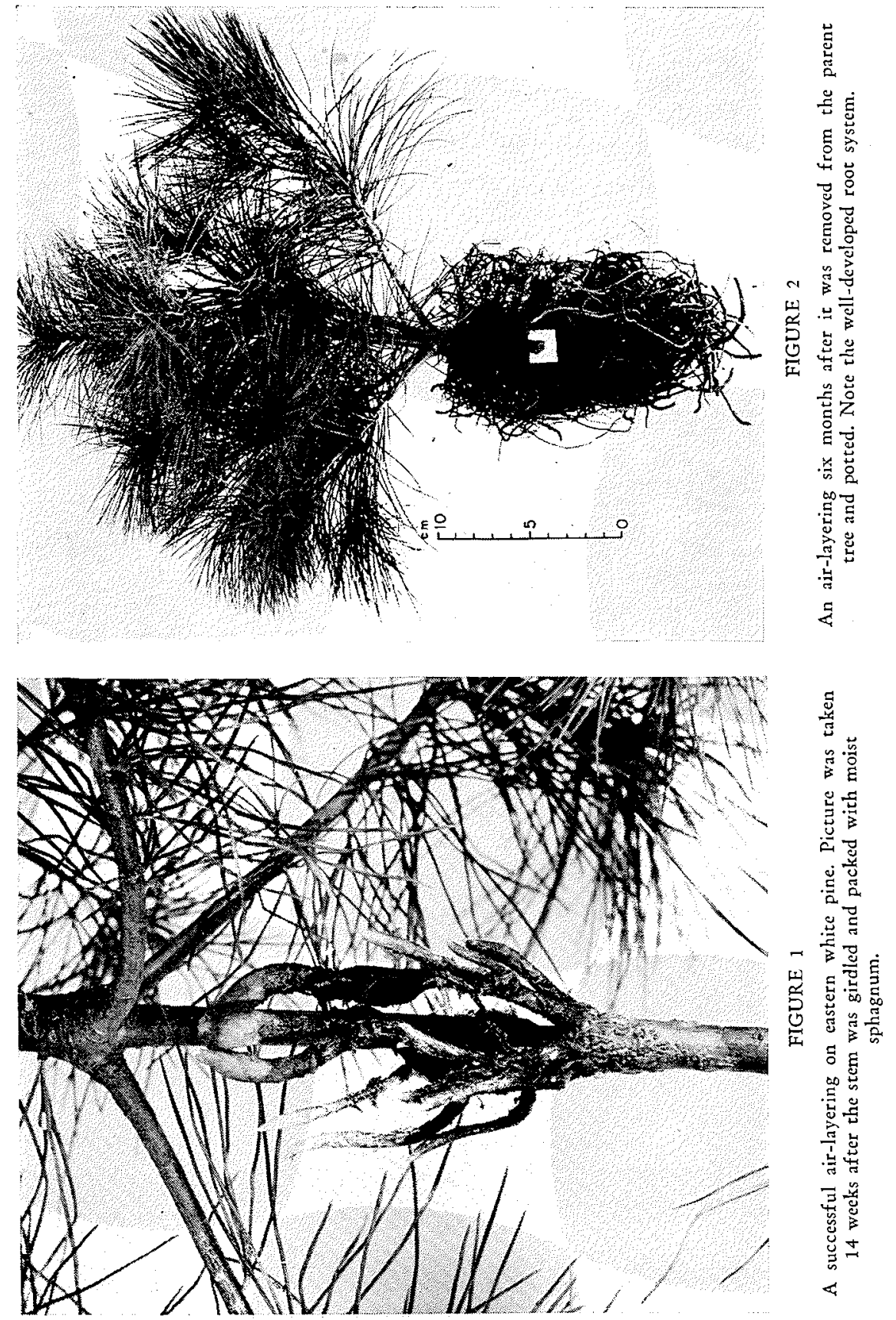